account of coronary occlusion in twins by Harvald and Hauge, who use the data of the Danish Twin Register and show that the occurrence of fatal coronary occlusion is genetically determined only to a very small degree in males, but to a much larger degree in females, because environmental factors known to influence its occurrence are more or less restricted to the male sex. In consequence only females who are heavily genetically predisposed will be affected, whereas environmental factors predominate in males.

Other interesting studies concern the heritability of the activity of serum enzymes, thyroid hormone level and measures of physical performance; it is surprising, however, that most of the authors use Holzinger's measure of 'heritability' which does not measure heritability in either of the senses which are used by geneticists today.

\section{G. BULMER}

Klassische und Molekulare Genetik. 2nd ed. By C. Bresch and R. Hausman. (Pp. vii $+373 ; 16$ plates + illustrations + tables. DM 38.00; \$10.50.) Berlin, Heidelberg, and New York: Springer Verlag. 1970.

The first edition of this book appeared in 1963 and proved an excellent, concise, and clear guide to present day genetics. Reprints in German and translations into Spanish, Italian, and Bulgarian testify to its worth. The frontispiece shows Mendel and Avery: a juxtaposition that summarizes the approach of this volume.

Intended as an introduction not only for students of biology, but also for the increasing number of disciplines which now draw on genetics, the text roams widely over many specialities, but adheres rigidly to its plan of giving the experimental data on which the generalizations are based. Logical deductions are most emphasized, whilst difficult and unsolved problems are indicated, The first 5 of the 12 chapters in this book deal with the cytological basis of heredity, and the succeeding 5 chapters with molecular aspects including an excellent account of enzyme systems and their bearing on regulatory mechanisms. The text is well rounded off by the two concluding chapters; one dealing with secondary gene effects and the other with the broad aspects of human genetics. Selective references-mercifully few in number-are as helpful as the text itself.

ARNOLD SORSBY

Genetic Counselling. By A. C. Stevenson and B. C. Davison. (Pp. vii +355 ; figures + tables. £2.75.) London: William Heinemann. 1970.

This book is written to help clinicians who are consulted by patients on genetic risks to their families, and to indicate to clinicians where it is appropriate to seek specialist genetic opinion. The authors adopt the traditional British viewpoint that decision rests with parents and that 'genetic counselling' consists of giving information on risks and not in giving advice. They also rightly believe that it is useful, as far as it is possible, to give an actual risk figure-a best estimate-rather than just say that the risk is high or low.

In the chapter on elementary genetics the authors sensibly use the terms dominant and recessive for genes as well as traits. This chapter includes a section on multifactorial threshold models, too often omitted from elementary books on human genetics, but the clue to a first understanding of the genetics of most common conditions. They make the point however that estimates from multifactorial models are no substitute for empirical risk figures. In deriving estimates of risks for single gene traits the authors make much use of algebra. This is neat and saves space but many non-mathematically minded clinicians will find the concepts difficult. It is perhaps because of this that the authors give no less than 20 pages of calculations in relation to examples of $\mathrm{X}$ linked conditions, and a further 10 pages in an appendix.

In the middle chapters the authors go systemically through the genetically and partly genetically determined disorders of the different bodily systems. Here an enormous amount of ground is covered. Inevitably individual human geneticists will have knowledge of special fields not available to the authors and will disagree about specific points. Several entities mentioned need further splitting into genetic types, for example the multiple epiphyseal and craniometaphyseal dysplasias. In contrast the reviewer has not seen or read a convincing report of a case of true achondroplasia that was recessive and so would not agree that 1 in 10 are recessive forms. Overall, however, the survey appears remarkably complete and accurate.

The authors include a valuable chapter on disorders and events in pregnancy, such as exposure to radiation. These are not strictly genetic, but are problems which are often raised in a genetic clinic. It is interesting that the authors recommend a termination of pregnancy if the fetus has received $25 \mathrm{rad}$ or more between the third and eighth week after conception. In contrast the risk of leukaemia from intrauterine exposure from the third month of pregnancy onward are not more than double for each rad of exposure.

\section{O. CARTER}

Human Genetics and Medicine. (Studies in Biology no. 20). By Cyril A. Clarke. (Pp. vi+74; figures + tables. $£ 0.75$; paperback $£ 0.45$.) London: Edward Arnold. 1970.

This book is directed primarily at the science sixth form schoolboy in order to show him that medical genetics provides many intriguing intellectual problems and now holds the key to the understanding of most common diseases. The topics Professor Clarke has chosen are therefore 'good stories' and they are well told. They include the controversy between the adherents of a monogenic and a polygenic inheritance for essential hypertension; the problem of maintenance of genetic polymorphism at blood type loci; the beginnings of the mapping of the autosomes; the striking examples of 